\title{
ÓLEO VEGETAL NO CONTROLE DO MÍLDIO EM VIDEIRAS CASTA ‘ISABEL PRECOCE’ EM SISTEMA BIOLÓGICO
}

\section{VEGETABLE OIL IN CONTROL MILDEW IN VINES 'ISABEL PRECOCE' IN ORGANIC SYSTEM}

\author{
Carla Garcia ${ }^{1}$, Cacilda Márcia Duarte Rios Faria ${ }^{1}$, Renato Vasconcelos Botelho ${ }^{1}$, Carla Daiane Leite ${ }^{2}$, \\ Kamila Cardozo de Souza ${ }^{1}$
}

\footnotetext{
${ }^{1}$ Universidade Estadual do Centro-Oeste, Departamento de Agronomia, Rua Camargo Varela de Sá, 03, 85040-080, Guarapuava, PR, Brasil. *Parte de dissertação de mestrado do primeiro autor.

${ }^{2}$ Universidade Tecnológica Federal do Paraná, Campus de Pato Branco, Departamento de Agronomia, Via do Conhecimento, Km 1, 85503-390, Pato Branco, PR, Brasil.
}

*corresponding author: Tel: +554298741316, e-mail: carlagarciaagro@gmail.com

(Manuscrito recebido em 10.04.2015. Aceite para publicação em 23.06.2015)

\section{RESUMO}

O trabalho teve como objetivo verificar o efeito de um óleo vegetal no controle do míldio da videira (Plasmopara viticola). Os tratamentos consistiram de concentrações crescentes de um óleo vegetal $(\mathrm{OV})$ emulsionável $\left(0 ; 0,05 ; 0,1 ; 0,2 ; 0,4\right.$ e $\left.0,8 \mathrm{~mL} \mathrm{~L}^{-1}\right)$ sendo o tratamento padrão realizado com calda bordalesa em ensaios in vitro em videiras da casta 'Isabel Precoce' (Vitis labrusca) em sistema de agricultura biológica. Foram realizados testes de germinação de esporângios de $P$. viticola, além da estimativa da área abaixo da curva de evolução da doença (AACED) do míldio em discos de folhas e em videiras mantidas em estufa e no campo, em dois anos consecutivos (2012/2013 e 2013/2014). Observou-se que as concentrações de OV reduziram a germinação do patógeno e a eficiência estava diretamente relacionada com o período de contato do produto com os esporângios. Nos discos de folha as concentrações 0,$2 ; 0,4$ e $0,8 \mathrm{~mL} \mathrm{~L}^{-1}$ reduziram acima de $80 \%$ a AACED do míldio. Em estufa a concentração $0,40 \mathrm{~mL} \mathrm{~L}^{-1}$ do composto testado não diferiu estatisticamente da calda bordalesa, reduzindo a AACEPD em mais de $60 \%$ nos dois ensaios. Em condições de campo, aplicações de OV entre 0,1 e $0,2 \mathrm{~mL} \mathrm{~L}^{-1}$ reduziram em até $61 \%$ a AACED do míldio em dois anos consecutivos. Ambas as modalidades não diferiram estatisticamente do tratamento padrão. Os resultados destes trabalhos indicaram que pulverizações da solução aquosa de óleo vegetal testada apresentaram resultados promissores em condições de campo, em estufa e em in vitro, embora com diferentes respostas para as concentrações testadas, condições de cultivo e ano.

\section{SUMMARY}

The study aimed to verify the effect of a vegetable oil in control of downy mildew (Plasmopara viticola). The treatments consisted of increasing concentrations of a vegetable oil $(\mathrm{OV})$ emulsifiable $\left(0 ; 0.05 ; 0.1 ; 0.2 ; 0.4\right.$ and $\left.0.8 \mathrm{~mL} \mathrm{~L}^{-1}\right)$ being carried out with the standard treatment of bordeaux mixture in vitro tests on grape variety 'Isabel Precoce' (Vitis labrusca) in organic farming system. Sporangia germination tests were performed for P. viticola, besides the estimate of the area under the curve of evolution of the disease (AUCED) the leaf discs mildew in vines and maintained in the greenhouse and field in two consecutive years (2012/2013 and 2013/2014). It was observed that the VO concentrations reduced the germination of the pathogen and the efficiency was directly related to the product contact time with the sporangia. In leaf discs concentrations $0.2 ; 0.4$ and $0.8 \mathrm{~mL} \mathrm{~L}^{-1}$ reduced up to $80 \%$ AUCED mildew. In greenhouse concentration $0.40 \mathrm{~mL} \mathrm{~L}^{-1}$ of the compound tested did not differ statistically from Bordeaux mixture, reducing AUCED in more than $60 \%$ in the two trials. In field conditions, VO applications between 0.1 and $0.2 \mathrm{~mL} \mathrm{~L}^{-1}$ reduced by up to $61 \%$ to AUCED mildew in two consecutive years. Both methods did not differ statistically from the standard treatment. The results of these studies indicate that spraying the aqueous solution of vegetable oil tested showed promising results under field conditions in the greenhouse and in vitro, although with different responses to the tested concentrations, cultivation conditions and year.

Palavras-chave: Vitis labrusca, Plasmopara viticola, gestão de doenças, oomiceto.

Key words: Vitis labrusca, Plasmopara viticola, disease management, oomycete.

\section{INTRODUÇÃO}

No Brasil, a viticultura ocupa uma área de 83.700 hectares, distribuídas desde o extremo sul até ao nordeste, em regiões de clima temperado, subtropical e tropical. A produção nacional anual de uva é aproximadamente de 1.400 toneladas, sendo que pouco mais de metade destina-se para consumo em

This is an Open Access article distributed under the terms of the Creative Commons Attribution License

(http://creativecommons.org/licenses/by/4.0), which permits unrestricted use, distribution, and reproduction in any medium, provided the original work is properly cited. 
fresco e em produtos transformado (Camargo et al., 2011; Mello, 2013).

A casta 'Isabel Precoce', amplamente cultivada, é uma mutação somática da cultivar 'Isabel', possuindo características similares com essa cultivar, porém a maturação dos cachos ocorre com antecedência de cerca de 33 dias, o que permite a ampliação do período de colheita e produção de produtos transformados. Também trata-se de uma uva rústica, tinta, fértil, com sabor peculiar das labruscas. As uvas provenientes desse clone podem ser destinadas para mesa, como matéria-prima para fabricação de doces e geléias, vinho, produção de destilados, vinagre e principalmente sumos (Camargo, 2004; Camargo et al., 2010).

Embora a 'Isabel Precoce' responda às exigências de transformação, há alguns entraves limitantes, especialmente em sistemas de produção biológica, como a suscetibilidade a fitopatógenos, destacando-se o oomiceto Plasmopara viticola, agente do míldio, que causa perdas no rendimento e na qualidade da uva (Sônego et al., 2006). O oomiceto ataca todos os órgãos verdes da planta, em especial as folhas, que têm a área fotossintética ativa reduzida e, consequentemente, queda da produtividade (Tavares e Cruz, 2002).

Para o controle do míldio da videira, utilizam-se basicamente fungicidas sintéticos que podem desencadear mutações e proliferações de populações de patógenos resistentes ao princípio ativo do produto, fitotoxicidade, poluição ambiental e resíduos nos cachos (Tripath e Dubey, 2004; Peruch et al., 2007; Pereira et al., 2009).

Algumas pesquisas têm testado produtos, derivados de plantas e microrganismos, com atividades fungistáticas e/ou fungitóxicas, visando substituir fungicidas, como a calda bordalesa, nas vinhas em modo de produção biológico (Rose et al., 2009; Dagostin et al., 2011). Substâncias encontradas nos óleos extraídos de sementes de plantas, como a presença de ácidos gordos insaturados, podem apresentar tal efeito (Lopes et al., 2010). Além disso, alguns óleos vegetais, comercializados como adjuvantes, favorecem a aderência de compostos na superfície foliar dificultando o desenvolvimento do patógeno (Zyl et al., 2010).

O potencial do óleo vegetal no controle de doenças foi observado por Junqueira et al. (2004), quando evidenciaram que mangas da cultivar 'Palmer' imersas em óleo vegetal apresentaram menor incidência de antracnose (Colletotrichum gloeosporioides) em pós-colheita, além de aumentar o tempo de prateleira das frutas.
$\mathrm{Na}$ videira, o óleo vegetal associado ao extrato de alho (Allium sativum) afetou negativamente a germinação de $P$. viticola e a severidade do míldio em condições de campo (Leite et al., 2011). Este óleo associado ao extrato aquoso de cinamomo (Melia azedarach) controlou outra importante doença da videira denominada de antracnose da videira (Silva et al., 2012b).

Neste sentido, o objetivo do trabalho foi verificar o efeito de concentrações de óleo vegetal emulsionável na germinação de $P$. viticola e no controle do míldio em videiras da casta'Isabel Precoce' em vinhas em modo de produção biológica e em estufa.

\section{MATERIAIS E MÉTODOS}

\section{Local dos ensaios}

Os ensaios foram conduzidos em Guarapuava, Estado do Paraná, região sul do Brasil. Com coordenadas geográficas de $25^{\circ} 23^{\prime} 43^{\prime}$ 'S, $51^{\circ} 30$ '29' 'W e a $1100 \mathrm{~m}$ de altitude, em solo classificado como latossolo bruno distroférrico de textura argilosa e clima $\mathrm{Cbf}$ subtropical mesotérmico úmido, conforme classificação de Koppën (Ayode, 1998). A temperatura e umidade relativa média, durante a condução dos ensaios, variaram entre $21,5^{\circ} \mathrm{C}$ a $25^{\circ} \mathrm{C}$ e $\geq 76,2 \%$ a $95 \%$, respetivamente.

\section{Efeito do óleo vegetal na germinação de Plasmopara viticola}

Folhas de videira, com sintomas típicos de míldio, foram colhidos em sacos de plástico e levados para o laboratório. Na sequência, foi adicionado sobre essas folhas $100 \mathrm{~mL}$ de água destilada esterilizada com 20 $\mu \mathrm{L}$ de Tween 80 e com uma alça de Drigalski foi realizado um esfregaço sobre o micélio para a libertação dos esporângios de $P$. viticola. A suspensão foi padronizada em 1x106 esporângios $\mathrm{mL}^{-1} \mathrm{em}$ câmara de Neubauer (hemocitômetro).

Os tratamentos foram constituídos pelas concentrações de $0 ; 0,05 ; 0,1 ; 0,2 ; 0,4$ e $0,8 \mathrm{~mL} \mathrm{~L}^{-1}$ de óleo vegetal emulsionável (Natur'l óleo $\AA$, Empresa Stoller do Brasil LTDA, contendo 93\% de óleo vegetal e $7 \%$ de ingredientes inertes) (OV), além de um tratamento padrão, utilizando em áreas onde se pratica agricultura biológica, como é o caso da calda bordalesa que tinha a seguinte constituição 0,6:0,3:100 (cal:sulfato cobre:água).

Alíquotas de $40 \mu \mathrm{L}$ de suspensão de esporângios e dos tratamentos foram colocadas em cavidades individuais em placas de teste de ELISA (Resende et al., 1997). Em seguida, as placas foram mantidas em câmara de crescimento a $25 \pm 1^{\circ} \mathrm{C}$, no escuro, durante 
2, 6, 12 e 24 horas, quando a germinação dos esporângios foi paralisada adicionando-se $20 \mu \mathrm{L}$ do corante azul algodão de lactofenol. Para cada período, avaliou-se a percentagem de esporângios germinados, observados aleatoriamente com auxílio do microscópico óptico de objetiva invertida, totalizando 400 esporângios, sendo considerados germinados aqueles que nitidamente apresentavam a libertação dos zoósporos.

O delineamento experimental foi inteiramente casualizado com sete tratamentos e quatro repetições sendo a parcela experimental constituída por placas para o teste ELISA. O ensaio foi realizado duas vezes.

Efeito do óleo vegetal no controle do míldio em discos de folhas da casta 'Isabel Precoce'

Discos de folhas jovens sadias da casta 'Isabel Precoce', com $5 \mathrm{~cm}$ de diâmetro, foram desinfestadas superficialmente com hipoclorito de sódio a $2 \%$ durante cinco segundos, sendo de seguida enxaguados em água destilada e secos à temperatura ambiente. Posteriormente, foram mergulhados durante um minuto nas soluções de $0 ; 0,05 ; 0,1 ; 0,2 ; 0,4$ ou 0,8 $\mathrm{mL} \mathrm{L} \mathrm{L}^{-1}$ de OV ou calda bordalesa na formulação 0,6:0,3:100 (cal: sulfato cobre:água). Em seguida, os discos foram distribuídos sobre espuma fenólica umedecida, contidas em bandejas plásticas, cobertas com sacos de plástico e, mantidas em câmara de crescimento tipo B.O.D. a $25 \pm 1^{\circ} \mathrm{C}$, com fotoperíodo de 12 horas.

Transcorridas 24 horas, inoculou-se por aspersão a suspensão de 1 x104 esporângios $\mathrm{mL}^{-1}$ de $P$. viticola sobre os discos de folha, seguindo-se um período de incubação em câmara de crescimento durante oito dias. Diariamente avaliou-se visualmente a severidade do míldio de acordo com a escala diagramática proposta por Azevedo (1997).

Os dados de severidade foram transformados em áreas abaixo da curva de evolução da doença (AACED) baseada na fórmula: AACED $=\Sigma$ (yi + $\mathrm{yi}+1) / 2 *(\mathrm{ti}+1-\mathrm{ti})$, onde: $\mathrm{n}=$ número de avaliações; $\mathrm{y}=$ severidade da doença $(\%) ; \mathrm{t}=$ tempo (dias) (Shaner e Finney, 1977).

O delineamento experimental foi inteiramente casualizado com sete tratamentos e cinco repetições com seis discos. O ensaio foi realizado duas vezes.

Efeito do óleo vegetal no controle do míldio na casta 'Isabel Precoce' em estufa

Estacas da casta 'Isabel Precoce' enxertadas sobre o porta-enxerto 'Paulsen 1103' foram plantadas em 23/10/2012, em vasos com capacidade de um litro contendo substrato comercial (Plantmax ${ }^{\circledR}$, composto por $60 \%$ de casca de pinus, $15 \%$ de vermiculite granulometria "fina" e 15\% "superfina" e 10\% de húmus). Os vasos foram mantidos em estufa sob irrigação por aspersão durante o período do ensaio. Após a rebentação das gemas, iniciou-se a aplicação dos quinzenais dos tratamentos, com pulverizador manual, até ao ponto de escorrimento, preferencialmente nas horas mais frescas do dia. Os tratamentos foram feitos de acordo com as seguintes concentrações de óleo vegetal: $0 ; 0,05 ; 0,1 ; 0,2 ; 0,4$ e $0,8 \mathrm{~mL} \mathrm{~L}^{-1}$ de $\mathrm{OV}$, além de um tratamento padrão com calda bordalesa, com a seguinte formulação 0,6:0,3:100 (cal:sulfato cobre:água).

No primeiro ano do ensaio (2012/2013) foram realizadas sete aplicações, entre 24/10/12 e 16/01/13, sendo cinco aplicações realizadas antes da inoculação do patógeno e duas depois. No segundo ano dos ensaios (2013/2014) realizaram-se oito aplicações (05/11/13 a 18/02/14), sendo sete antes e uma após a inoculação. A época de inoculação variou devido à dependência do desenvolvimento natural do míldio, ou seja, da disponibilidade de inóculo em condições de campo.

As avaliações da severidade do míldio, baseadas na escala de Azevedo (1997), foram realizadas em cinco folhas por planta previamente identificadas. Estes dados foram transformados em AACED (Shaner e Finney, 1977).

O delineamento experimental adotado foi o de blocos casualizados com sete tratamentos e seis repetições, sendo cada vaso uma parcela experimental.

\section{Efeito do óleo vegetal no controle do míldio na casta 'Isabel Precoce' em condições de campo}

Estacas da casta 'Isabel Precoce' enxertadas sobre 'Paulsen 1103', conduzidas em espaldeira, com espaçamento de $1,2 \times 2,5 \mathrm{~m}$, foram plantadas em 23/10/2012. Os tratamentos consistiram em pulverizações quinzenais com as seguintes concentrações de óleo vegetal: $0 ; 0,1 ; 0,2 ; 0,4$ e 0,8 $\mathrm{mL} \mathrm{L}^{-1}$ de OV, havendo a acrescentar um tratamento padrão à base de calda bordalesa preparada na proporção de 0,6: 0,3: 100 (cal: sulfato cobre: água). As aplicações foram realizadas com pulverizador manual e dirigidas às folhas, até ao ponto de escorrimento, iniciando-se as aplicações desde o início da rebentação das gemas, o que teve lugar no período compreendido entre $17 / 10 / 12$ a $30 / 01 / 13$ no primeiro ano dos ensaios, totalizando nove aplicações; e no segundo ano de 12/11/2013 a 21/01/14, com seis aplicações.

As avaliações visuais da severidade da doença foram iniciadas quando surgiram os primeiros sintomas da doença segundo a escala proposta por Azevedo 
(1997). Os dados foram transformados em AACED (Shaner e Finney, 1977). As avaliações foram realizadas semanalmente, totalizando cinco avaliações, no período de 02/01/13 a 30/01/13, e no segundo ano de ensaios de 30/12/12 a 27/01/14, em cinco folhas pré-marcadas em cada planta.

O delineamento experimental foi feito em blocos casualizados com seis tratamentos e cinco repetições, sendo a parcela experimental constituída por uma planta.

\section{Análises estatísticas}

Os resultados obtidos foram submetidos à análise de variância e, quando significativo realizou-se a regressão polinominal e comparação de médias pelo teste de Tukey ao nível de 5\% de probabilidade, com recurso ao programa estatístico SISVAR (Ferreira, 2011).

\section{RESULTADOS E DISCUSSÃO}

\section{Efeito do óleo vegetal na germinação de Plasmopara viticola}

Os tratamentos com OV e calda bordalesa foram eficazes na redução da germinação de esporângios de $P$. viticola. Em todos os períodos de avaliação, houve efeito quadrático para a percentagem de germinação de esporângios de $P$. viticola em função das concentrações de OV. A maior dose $\left(0,8 \mathrm{~mL} \mathrm{~L}^{-1}\right)$ de OV reduziu em $61 \%$, $87 \%$, $85 \%$ e $77 \%$ a germinação do patógeno da videira após 2, 6, 12 e 24 horas de incubação, respetivamente, quando comparado com o tratamento testemunha. Além disso, essa concentração não diferiu estatisticamente do tratamento padrão com calda bordalesa, que reduziu em mais de $70 \%$ a germinação dos esporângios em todos os períodos (Figura 1).
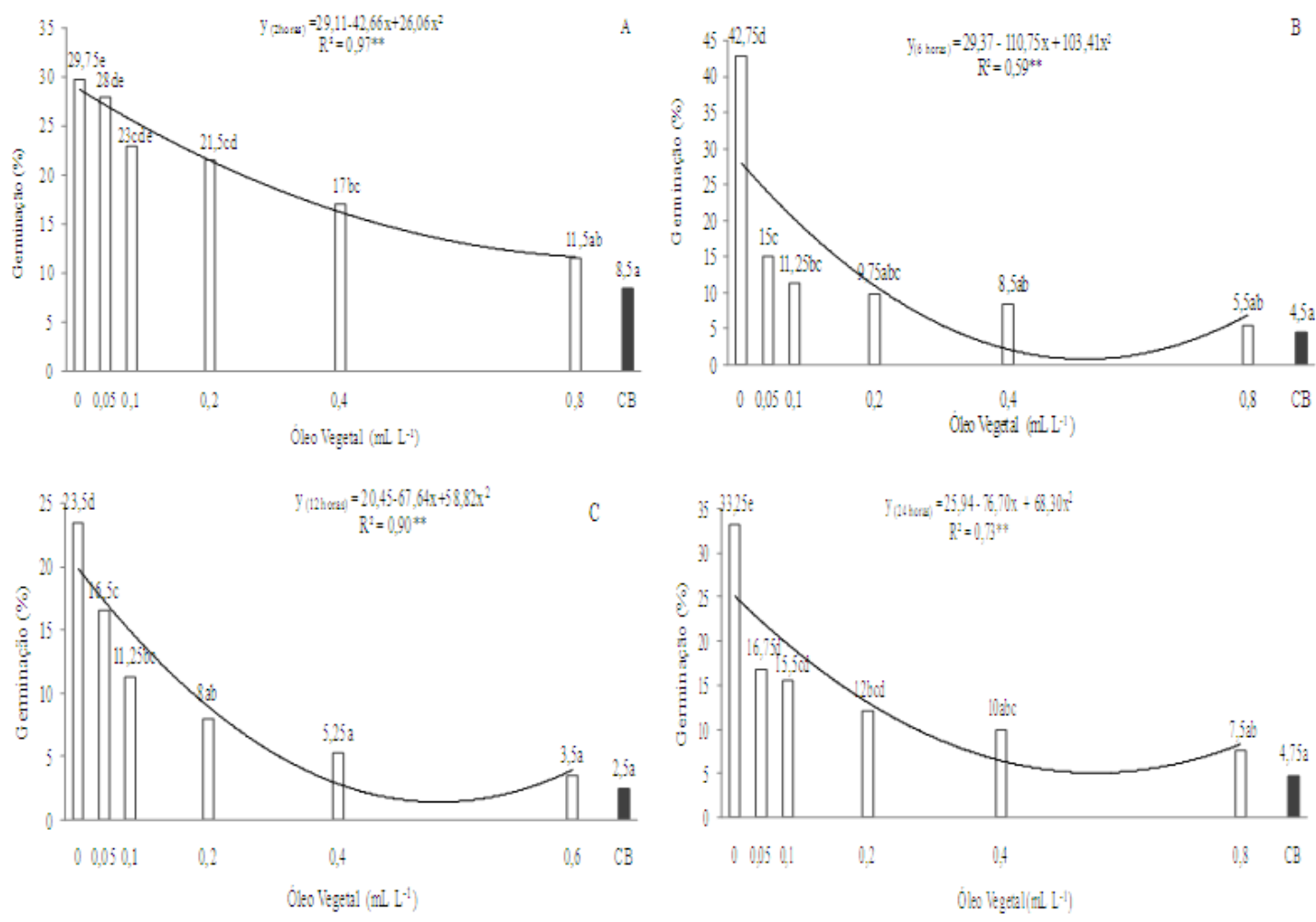

Figura 1. Germinação de esporângios de Plasmopara viticola submetidos às doses de 0,$05 ; 0,1 ; 0,2 ; 0,4$ e $0,8 \mathrm{~mL} \mathrm{~L}^{-1}$ de óleo vegetal e os tratamentos testemunha somente água e padrão com calda bordalesa, nos períodos de: (A) 2 horas; (B) 6 horas; (C) 12 horas e (D) 24 horas (Guarapuava-PR, 2014). CB: Calda Bordalesa ** Significativo estatisticamente a 5\% de probabilidade

Germination of Plasmopara viticola sporangia submitted to $0.05 ; 0.1 ; 0.2 ; 0.4$ and $0.8 \mathrm{~mL} \mathrm{~L}^{-1}$ doses of vegetable oil and control treatment with only water and standard Bordeaux mixture , the periods (A) 2 hours; (B) 4 hours; (C) 6 hours; (D) 12 hours and (E) 24 hours (Guarapuava-PR 2014). CB: Bordelaise Sauce. ** Statistically significant at 5\% probability 
O óleo vegetal apresentou efeito fungitóxico inibindo a germinação de $P$. viticola, sendo que este efeito poderia estar relacionado com outros fatores, como a sua composição em ácido linoleico que pode atingir os 57\% (Kitamura, 1984). Este ácido gordo é encontrado em altos níveis em plantas de milho resistentes a patógenos causadores de grãos ardidos (Fusarium verticiloides, Stenocarpella maydis, S. macrospora), pois quando ocorre a oxigenação, através da enzima lipogenase, aldeídos voláteis são libertados e impedem o desenvolvimento de patógenos (Zeringue et al., 1996), o que pode ter acontecido em esporângios de $P$. viticola no presente trabalho.

As concentrações de OV estimadas, pela maximização da função, para a mínima germinação de esporângios de $P$. viticola foram de 0,$81 ; 0,53$; 0,57 e $0,56 \mathrm{~mL} \mathrm{~L}^{-1}$ de OV para os períodos de 2, 6, 12 e 24 horas, respetivamente. A eficiência do óleo foi verificada por Souza et al. (2012) que observaram uma redução do índice de velocidade do crescimento micelial de Elsinoe ampelina proporcional ao aumento da dose do OV, obtendo-se valores de controle que atingiram os $31 \%$ com $0,8 \mathrm{~mL} \mathrm{~L}^{-1}$ de OV.

Efeito do óleo vegetal no controle do míldio em discos de folhas da casta 'Isabel Precoce'

Os tratamentos com OV afetaram o desenvolvimento do míldio em discos foliares de videira. As concentrações 0,$2 ; 0,4$ e $0,8 \mathrm{~mL} \mathrm{~L}^{-1}$ de OV reduziram AACED em 82,5\%, 83,3\% e 85\%, respetivamente, em relação ao tratamento testemunha, não diferindo do tratamento padrão com a calda bordalesa, que reduziu em 66,4\% a AACED (Figura 2). A dose de OV estimada para mínima AACED, pela maximização da função foi de $0,55 \mathrm{~mL} \mathrm{~L}^{-1}$. A eficiência do óleo vegetal na gestão da doença foi verificada, por Junqueira et al. (2003), em bananas com antracnose (C. musae), destacando o retardamento do amadurecimento dos frutos.

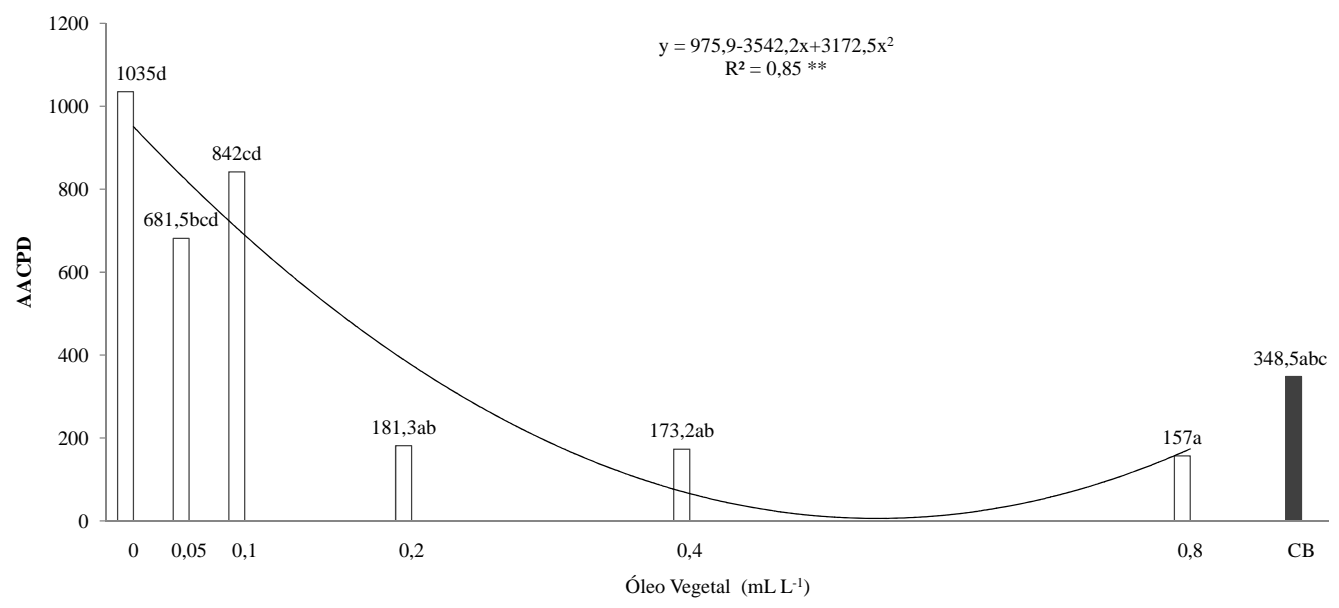

Figura 2. Área abaixo da curva do progresso da doença (AACPD) do míldio em discos de folha de videira cv. 'Isabel Precoce' tratadas com as doses de 0,$05 ; 0,1 ; 0,2 ; 0,4$ e $0,8 \mathrm{~mL} \mathrm{~L}^{-1}$ de óleo vegetal, tratamento testemunha (somente água) e calda bordalesa (Guarapuava-PR, 2014). CB: Calda Bordalesa ** Significativo estatisticamente a 5\% de probabilidade

Area under the disease progress curve (AUDPC) downy mildew of grapevine cv. leaf discs 'Isabel Precoce' treated with doses of 0.05; 0.1; 0.2; 0.4 and $0.8 \mathrm{ml} \mathrm{L}^{-1}$ plant oil control (only water) and Bordeaux mixture (PR-Guarapuava, 2014). CB: Bordelaise Sauce. ** Statistically significant at $5 \%$ probability

\section{Efeito do óleo vegetal no controle do míldio na casta 'Isabel Precoce' em estufa}

Em estufa OV reduziu a severidade do míldio, embora em concentrações distintas. No primeiro ensaio, houve um efeito significativo das concentrações para a regressão linear negativa, sendo que 0,$05 ; 0,4$ e $0,8 \mathrm{~mL} \mathrm{~L}^{-1}$ de $\mathrm{OV}$ controlou em $56 \%$, $64 \%$ e $74 \%$ a AACED, respetivamente, não diferindo significativamente do tratamento padrão com calda bordalesa que apresentou uma diminuição de 94,2\% (Figura 3A).

No segundo ensaio, no entanto, houve significância para regressão quadrática em função das concentrações de OV. Os tratamentos com 0,1; 0,2 e $0,4 \mathrm{~mL} \mathrm{~L}^{-1}$ de OV, apresentaram redução de $19 \%$, $60,2 \%$ e 60,4\%, respetivamente, da AACED do míldio da videira, não diferindo significativamente do tratamento padrão com calda bordalesa, que obteve 
uma redução de 83,5\%. A dose estimada de OV para a mínima AACED, através da maximização da função, foi de $0,55 \mathrm{~mL} \mathrm{~L}^{-1}$ para o primeiro ensaio e de $0,4 \mathrm{~mL} \mathrm{~L}^{-1}$ para o segundo (Figura 3B).
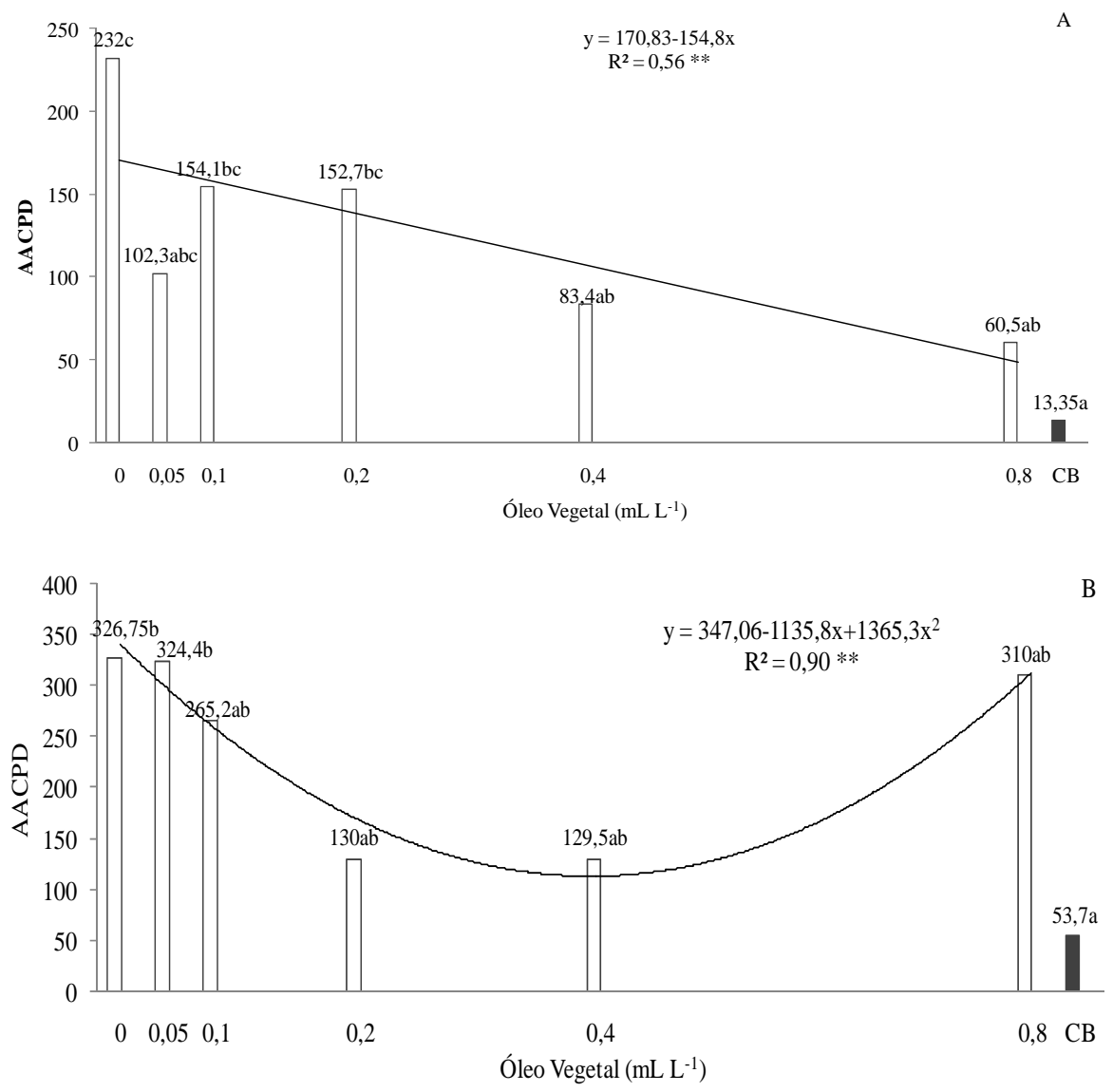

Figura 3. Área abaixo da curva do progresso da doença (AACPD) do míldio em videiras cv. 'Isabel Precoce’ em condições de casa de vegetação, tratadas com as doses de 0,05; 0,1; 0,2; 0,4 e 0,8 $\mathrm{mL} \mathrm{L}^{-1}$ de óleo vegetal. Primeiro ciclo (2012/2013) em A e segundo (2013/2014) em B (Guarapuava-PR). CB: Calda Bordalesa.** Significativo estatisticamente a $5 \%$ de probabilidade.

Area under the disease progress curve of the disease (AUDPC) of mildew in grapevine. Isabel Precoce in house conditions of vegetation, treated with doses of $0.05 ; 0.1 ; 0.2 ; 0.4$; and $0.8 \mathrm{~mL} \mathrm{~L}^{-1}$ of vegetable oil. First cycle (2012/2013) in A and second (2013/2014) in B (Guarapuava-PR). CB: Bordelaise Sauce. ** Statistically significant at $5 \%$ probability.

Os resultados deste trabalho corroboram com os verificados por Dagostin et al. (2011) que apontam para $87,8 \%$ de eficiência de controle do míldio da videira em estufa. Esses autores verificaram que o óleo apresenta a mesma eficiência do cobre (presente na calda bordalesa). Zyl et al. (2010) enfatizaram que o adjuvante Solitaire ${ }^{\circledR}$ (composto por silicone e óleo vegetal) permite maior aderência do produto na superfície foliar, o que prejudica o desenvolvimento de patógenos como $P$. viticola.

Efeito do óleo vegetal no controle do míldio na casta 'Isabel Precoce' em condições de campo

Nos dois ensaios o OV foi efetivo no controle do míldio, havendo um efeito quadrático em função das concentrações de OV, tendo-se observado no primeiro ensaio que a dose de $0,1 \mathrm{~mL} \mathrm{~L}^{-1}$ de $\mathrm{OV}$ apresentou uma redução da AACED de $61,4 \%$, não diferindo do tratamento padrão com calda bordalesa, que reduziu em $92,7 \%$. No segundo ensaio a dose 0,2 $\mathrm{mL} \mathrm{L} \mathrm{L}^{-1}$ de OV proporcionou uma redução de $50 \%$ da AACED do míldio, não diferindo do tratamento padrão que reduziu em $78,5 \%$. No entanto é de notar que a maior concentração $\left(0,80 \mathrm{~mL} \mathrm{~L}^{-1}\right)$ diminuiu a AACED do míldio em apenas $15,15 \%$ no primeiro ensaio e 22,38\% no segundo (Figura 4 A e B), facto que pode estar relacionado a alguma fitotoxidez do produto em concentrações mais altas, que consequentemente tornou a planta mais vulnerável a doença. As concentrações estimadas de OV para a 
menor AACED foram de $0,38 \mathrm{~mL} \mathrm{~L}^{-1}$ e $0,45 \mathrm{~mL} \mathrm{~L}^{-1}$ no primeiro e segundo ensaio, respetivamente (Figura 4 A B). Silva et al. (2012a) observaram que em condições de campo (videiras da casta 'Isabel'), a aplicação isolada do óleo vegetal na dose de $2,5 \mathrm{~mL}$ L- ${ }^{1}$ proporcionou uma redução de $76,3 \%$ na AACED do míldio em relação à testemunha absoluta (somente água), enquanto que em outro ensaio, verificou-se que o óleo vegetal proporcionou uma redução de $64,0 \%$ na AACED para a antracnose da videira (Silva et al., 2012b). Leite et al. (2011) verificaram que o óleo vegetal na dose de $2,5 \mathrm{~mL} \mathrm{~L}^{-1}$ reduziu em $52 \%$ a AACED do míldio da videira em relação ao tratamento testemunha. Em outros patossistemas, o óleo vegetal de sementes de Brassicaceae destacou-se no controle do oídio do melão, quando comparado com fungicidas convencionais, como pentaconazole, miclobutanil, azoxystrobin e enxofre (Candido et al., 2014).
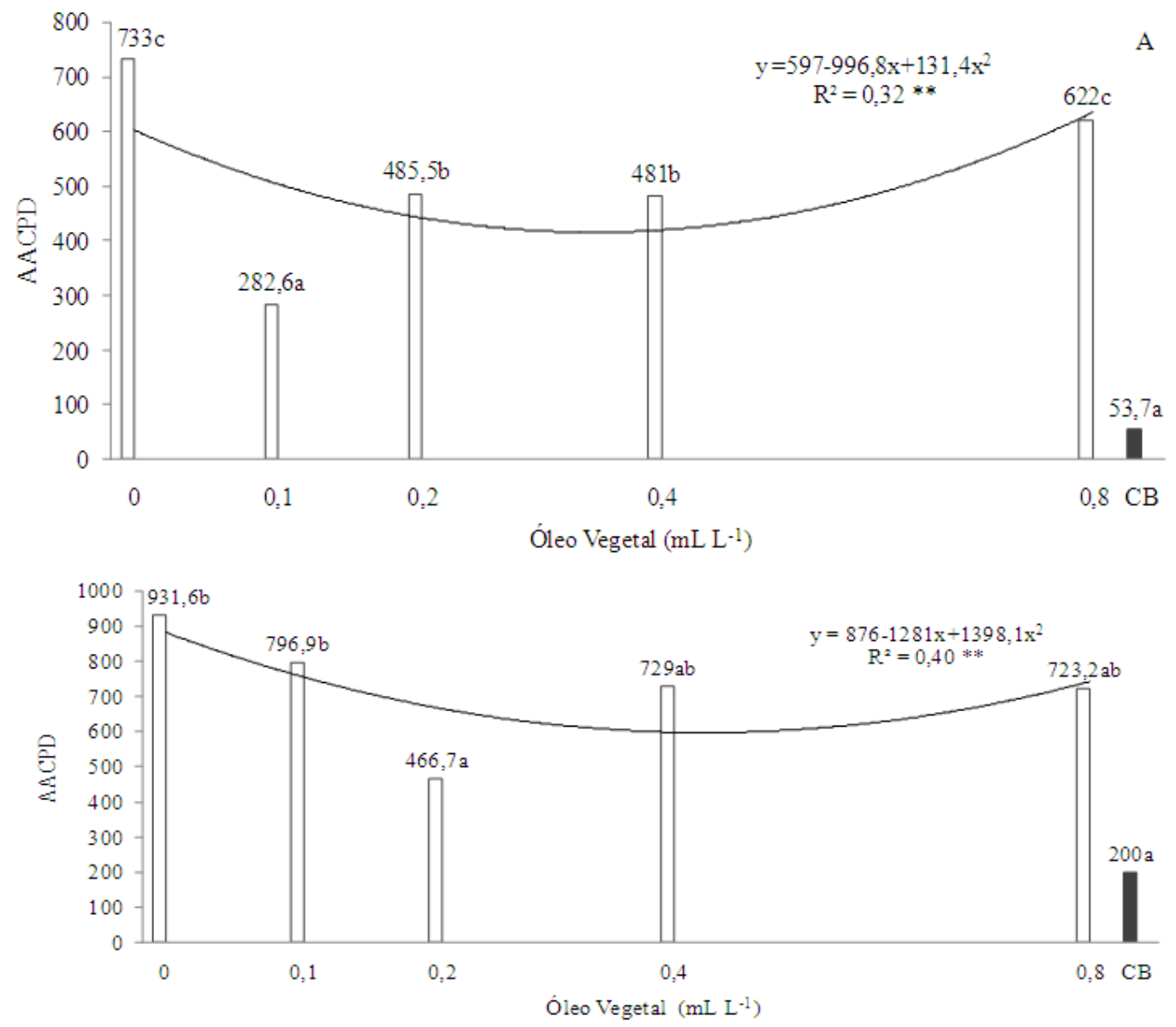

Figura 4. Área abaixo da curva do progresso da doença (AACPD) do míldio em videiras cv. 'Isabel Precoce' em condições de campo, tratadas com as doses de 0,05; 0,1; 0,2; 0,4 e 0,8 $\mathrm{mL} \mathrm{L}^{-1}$ de óleo vegetal. Primeiro ciclo (2012/2013) em A e segundo (2013/2014) em B (Guarapuava-PR). CB: Calda Bordalesa. ** Significativo estatisticamente a $5 \%$ de probabilidade.

Area under the disease progress curve of the disease (AUDPC) of mildew in grapevine. 'Isabel Precoce' in field conditions, treated with doses of 0.05; 0.1; 0.2; 0.4 and $0.8 \mathrm{~mL} \mathrm{~L}^{-1}$ of vegetable oil. First cycle (2012/2013) in A and second (2013/2014) in B (Guarapuava-PR). CB: Bordelaise Sauce. ** Statistically significant at $5 \%$ probability.

\section{CONCLUSÕES}

De maneira geral, tanto no ensaio em estufa como em condições de campo, aplicações repetidas com as concentrações mais altas de óleo vegetal, não apresentaram o mesmo efeito positivo no controle do míldio nos dois ensaios efetuados. Analisando os resultados de todos os ensaios conduzidos, a dose de $0,4 \mathrm{~mL} \mathrm{~L}^{-1}$ de $\mathrm{OV}$, foi a que apresentou os resultados mais consistentes e constantes em relação ao controle do míldio, considerando os aspetos 
agronômicos. Novas pesquisas devem ser conduzidas, com aplicações com intervalos menores e concentrações mais baixas de $\mathrm{OV}$ procurando encontrar valores de eficiência mais altos sobretudo em condições de campo, representando deste modo uma alternativa com menor impacto ambiental para o controle das doenças da videira, em particular do míldio.

\section{AGRADECIMENTOS}

À Coordenação de Aperfeiçoamento Pessoal de Nível Superior (CAPES) pela concessão da bolsa à primeira autora.

\section{REFERÊNCIAS BIBLIOGRÁFICAS}

Ayode J.O., 1998. Introdução à climatologia para os trópicos. 332 p. Bertrand Brasil, Rio de Janeiro.

Azevedo L.A.S., 1997. Manual de quantificação de doenças de plantas. 114 p. Novartis, São Paulo.

Camargo A.C., 2004. 'Isabel Precoce': Alternativa para a viticultura brasileira. Boletim Técnico 6. 6 p. EMBRAPA CNPUV, Bento Gonçalves.

Camargo U.A., Maia J.D.G., Ritschel P., 2010. Embrapa Uva e Vinho: Novas Cultivares Brasileiras de Uva. 64 p. Embrapa, Bento Gonçalves.

Camargo U.A., Tonietto J., Hoffmann A., 2011. Processos na viticultura brasileira. Revista Brasileira de Fruticultura, v.e., 144149.

Candido V., Campanelli G., Viggiani G., Lazzeri L., Ferrari V., Camele I., 2014. Melon yield response to the control of powdery mildew by environmentally friendly substances. Sci. Hortic., 166, 70-77.

Dagostin S., Schärer H.J., Pertot I., Tamm L., 2011. Are there alternatives to copper for controlling grapevine downy mildew in organic viticulture? Crop Prot., 30, 776-788.

Ferreira D.F., 2011. SISVAR: A computer statistical analysis system. Ciência e Agrotecnologia, 35, 1039-1042.

Junqueira N.T.V., Chaves R., Nascimento A.C., Ramos V.H.V., Peixoto J.R., Junqueira L.R., 2004. Efeito de óleo de soja no controle da antracnose e na conservação da manda cv. Palmer em pós-colheita. Revista Brasileira de Fruticultura, 26, 222-225.

Junqueira N.T.V., Silva A.P., Misael L.P., Lage D.A., Silva D.M., Fialho J., Junqueira L.P. 2003. Potencial de defensivos biológicos no controle da antracnose e na conservação de bananas em póscolheita. Boletim de pesquisa e desenvolvimento 94. 14 p. EMBRAPA, Planaltina.

Kitamura K., 1984. Biochemical of lipoxigenase lacking mutantes, L1-Less, L-2 Less and L-3Less soybeans. Agric. Biol. Chem., 48, 2339-2346.
Leite C.D., Botelho R.V., Faria C.M.D.R., Maia A.J., 2011. Extrato de alho e óleo vegetal no controle do míldio da videira. Revista Brasileira de Fruticultura, 33, 429-436.

Lopes L.M., Sevilha A.C., Feleiro F.G., Silva D.B., Vieira, R.F., Agostini-Costa T., 2010. Estudo comparativo do perfil de ácidos graxos em sementes de passiflora nativas do cerrado brasileiro. Revista Brasileira de Fruticultura, 32, 498-506.

Mello L.M.R., 2013. Vitivinicultura Brasileira: Panorama 2012. Comunicado Técnico 137. 5 p. EMBRAPA CNPUV, Bento Gonçalves.

Pereira D.F., Neves W.S., Zambolim L., 2009. Resistência de fungos a fungicidas inibidores de Quinona. Revista Tropica, 3, 24 34.

Peruch L.A.M., Medeiros A.M., Bruna E.D., Stadinik K.M., 2007. Biomassa cítrica, extrato de algas, calda bordalesa e fosfitos no controle do míldio da videira cv. Niágara Branca. Revista de Ciências Agroveterinárias, 6, 143-148.

Resende M.C., Oliva C.R., Feldman M.L., Castagnaro A.P., Canal L., 1997. A sunflower leaf antifungal peptide activa against Sclerotinia sclerotiorum. Physiol. Plant., 100, 178-182.

Rose G., Lane S., Jordan R., 2009. The fate of fungicide and insecticide residues in Australian wine grape by-products following field application. Food Chem., 117, 634-640.

Shaner G., Finney R., 1977. The effect of nitrogen fertilization on the expression of slow mildewing resistance in Knox Wheat. Phytopathology, 67, 1051-1056.

Silva C.M., Botelho R.V., Faria C.M.R.D., 2012b. Utilização do extrato aquoso de cinamomo no controle da antracnose da videira. Summa Phytopathol., 38, 312-318.

Silva C.M. da, Botelho R.V., Faria C.M.R.D., Stadler T.P., 2012a. Controle alternativo do míldio da videira com extrato aquoso de cinamomo e óleo vegetal. Arquivos do Instituto Biológico, 79, $587-$ 594.

Sônego O.R., Garrido L. da R., Grigoletti Júnior A., 2006. Principais doenças fúngicas da videira do sul do Brasil. Circular Técnica 56. 34 p. EMBRAPA CNPUV, Bento Gonçalves.

Souza K.C. de, Garcia C., Leite C.D., Faria C.M.D.R., Botelho R.V. 2012. Influencia de óleo vegetal no crescimento micelial de Elsinoe ampelina agente causal da antracnose da videira (Vitis sp.). In: Congresso do Setor de Ciências Agrárias e Ambientais da Unicentro: Sustentabilidade e sociedade do conhecimento, 1. Guarapuava, PR. Resumos.

Tavares S.C.C.H., Cruz S.C., 2002. Doenças causadas por fungos. In: Lima M.F., Mereira W.A. Frutas do Brasil: Uva de mesa: Fitossanidade. 9-26. Embrapa informação tecnológica.

Tripathi P., Dubey N.K., 2004. Exploitation of natural products as alternative strategy to control postharvest fungal rotting of fruit and vegetables. Biol. Control, 32, 235-245.

Zeringue H.J. Brown R.L., Neucere J.N., 1996. Relationship between C6-C12 alkanal and alkenal volatile contents and resistance of maize genotypes to Aspergillus flavus and aflatoxin production. J. Agric. Food Chem., 44, 403-407.

Zyl S.A.V., Brink J., Calitz F.J., Fourie P.H., 2010. Effects of adjuvants on deposition efficiency of fenhexamid sprays applied to Chardonnay grapevine foliage. Crop Prot., 29, 843-852. 